\title{
New information on ornithopod dinosaurs from the Late Jurassic of Portugal
}

Filippo Maria Rotatori, Miguel Moreno-Azanza, and Octávio Mateus

Acta Palaeontologica Polonica 65 (1), 2020: 35-57 doi:https://doi.org/10.4202/app.00661.2019

Ornithopods are one of the most speciose group of herbivorous dinosaurs, rising during the Jurassic and getting extinct at the Cretaceous-Paleogene boundary. However, most of the attention has been given to derived forms (hadrosaurids). Herein, cranial and post-cranial ornithopod material from the Upper Jurassic Lourinhã Formation and housed at Museu da Lourinhã is described and discussed. Comparison and phylogenetic analyses has allowed the attribution of the material either to Dryosauridae or to Ankylopollexia. The large-sized taxa conservatively ascribed to Ankylopollexia, resemble more closely Early Cretaceous styracosternans than Late Jurassic taxa. Due to the lack of autapomorphic characters, it was not possible to assign the material to any of the two valid Jurassic ornithopod Portuguese species, Draconyx loureiroi and Eousdryosaurus nanohallucis, although phylogenetic analyses hint a close relationship between the Lourinhã dryosaurid material and E. nanohallucis. Principal Component Analysis plotting limb bones proportions indicates a not fully mature ontogenetic stage for the Portuguese specimens. Comparing the Portuguese ornithopod fauna with the one in Morrison Formation and Kimmeridge Clay Formation, it is remarked the key-role of Portugal to understand biogeographic patterns in the distribution of iguanodontians.

Key words: Dinosauria, Ornithischia, Iguanodontia, taxonomy, systematics, biogeograhy, Jurassic, Lourinhã Formation, Portugal.

Filippo Maria Rotatori [filippo.rotatori.93@gmail.com], Miguel Moreno-Azanza

[mmazanza@gmail.com], and Octávio Mateus [omateus@ fct.unl.pt], GeoBioTec, Department of Earth Sciences, Faculdade de Ciências e Tecnologia, FCT, Universidade Nova de Lisboa, 2829-516 Caparica, Portugal; Museu da Lourinhã, Espaço Novapaleo, Rua João Luis de Moura 95, 2530-158 Lourinhã, Portugal.

This is an open-access article distributed under the terms of the Creative Commons 
Attribution License (for details please see creativecommons.org), which permits unrestricted use, distribution, and reproduction in any medium, provided the original author and source are credited.

\author{
Fof Full text $(1,097.3 \mathrm{kB})$ । \\ PaF Supplementary file $(1,045.6 \mathrm{kB})$
}

